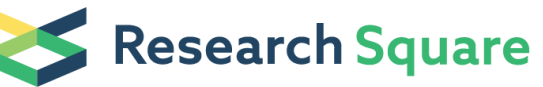 \\ Preprints are preliminary reports that have not undergone peer review. \\ They should not be considered conclusive, used to inform clinical practice, or referenced by the media as validated information.
}

\section{The hidden risk of ionizing radiation in the operating room: A survey among 258 orthopaedic surgeons in Brazil}

Robinson Esteves Pires ( $\nabla$ robinsonestevespires@gmail.com )

Universidade Federal de Minas Gerais https://orcid.org/0000-0002-3572-5576

Igor Guedes Nogueira Reis

Universidade Federal de Minas Gerais

Ângelo Ribeiro Vaz de Faria

Universidade Federal de Minas Gerais

Vincenzo Giordano

Hospital Municipal Miguel Couto

Pedro José Labronici

Universidade Federal Fluminense

William Dias Belangero

Universidade Estadual de Campinas

\section{Research}

Keywords: Radiation Exposure; lonizing Radiation; Radiation; Orthopedics; Scatter Radiation; Radiation Protection; Occupational Exposure; Orthopaedic Surgeon

Posted Date: March 24th, 2020

DOI: https://doi.org/10.21203/rs.2.21599/v2

License: (c) (i) This work is licensed under a Creative Commons Attribution 4.0 International License.

Read Full License

Version of Record: A version of this preprint was published at Patient Safety in Surgery on April 22nd, 2020. See the published version at https://doi.org/10.1186/s13037-020-00238-6. 


\section{Abstract}

Background: This study aims to assess orthopedic surgeon knowledge in Brazil about ionizing radiation and its health implications on surgical teams and patients. Methods: A 15-question survey on theoretical and practical concepts of ionizing radiation was administered during the 23rd Brazilian Orthopaedic Trauma Association annual meeting. The survey addressed issues within orthopedic surgery, such as radiation safety concepts, protection, exposure, as well as the participant gender.Participants were either orthopedic surgeons or orthopedic surgery residents working at institutions in Brazil. Results: One thousand surveys weredistributed,and 258 were answered completely ( $25.8 \%$ response rate).Only $5.8 \%$ of participants used basic radiation protection equipment (apron, thyroid shield, and radiation protection glasses); $47.3 \%$ used a dosimeter; $2.7 \%$ reached the annual maximum permissible radiation dose; $10.5 \%$ knew the period of increased risk to fetal gestation; 5.8\% knew the maximum permissible radiation dose during pregnancy; $58.5 \%$ knew that the hands, eyes, and thyroid are the most exposed areas and at greater risk of radiation-related lesions; $25.2 \%$ knew the safe distance from a radiation-emitting tube is 3 meters or more; $44.2 \%$ knew the safest positioning of the radiation-emitting tube; $25.2 \%$ knew that smaller tubes emit greater radiation at the entrance dose to magnify the image; and $55.4 \%$ knew that the surgery team receives more scattered radiation in surgical procedures performed on obese patients.

Conclusion: This study revealed inadequate theoretical and practical knowledge about radiation exposureamong orthopaedic surgeons in Brazil. Only a minority of orthopaedic surgeons used basic radiation protection equipment (apron, thyroid shield, and radiation protection glasses). No significant differences in knowledge were found when comparing all orthopedic surgery specialties. Our findings indicate an urgent need for education to increase knowledge among orthopaedic surgeons about the hazards of ionizing radiation. Personal protection and implementation of the ALARA (as low as reasonably achievable) protocol in daily practice are important behaviors to prevent the harmful effects of ionizing radiation.

\section{Background}

In the last few decades, the number of surgeries, new technologies, and diagnostic tools has been increasing along with awareness of radiation exposure risks. In the United States, medical radiation exposure has increased $600 \%$ since 1980 , and it is estimated that about $2-3 \%$ of future cancers could be related to previous ionizing radiation exposure [1]. Assessing what professionals know and do to protect themselves and their patients is important to prevent undesired outcomes while using the latest and best technologies.

Although the harmful effects of radiation on human biology are very well known, the literature contains conflicting evidence concerning some effects of ionizing radiation on professionals [2-4]. Despite awareness of long-term radiation effects, health professionals may still neglect aspects of radiation protection in their daily work. 
Fluoroscopy is one of the most valuable tools in the orthopaedic surgeon arsenal, especially for fracture reduction and proper implant placement. Correct $\mathrm{C}$-arm operation via clear communication with the technician is crucial to obtain useful images. Furthermore, orthopaedic surgeons should aim to keep radiation exposure "as low as reasonably achievable" (ALARA), to decrease risks to both patient and staff [2-6].

The aim of this study is to assess the knowledge of orthopedic surgeons in Brazil on ionizing radiation and protection recommendations, broken down by specialty. The study also evaluates some implications regarding the health of the surgeon, surgical team, and patients and includes some controversial topics found in the literature.

\section{Methods}

During the $23^{\text {rd }}$ Brazilian Orthopaedic Trauma Association annual meeting, we distributed 1,000 surveys containing 15 questions (Appendix 1) regarding theoretical and practical concepts of ionizing radiation. Inclusion criteria were being an orthopedic surgeon or orthopedic surgery resident at an institution in Brazil. In total, 258 surveys were completed.

Contingency tables were used for data description. Categorical variables were tested by Chi-square test, and results were considered significant when $p<0.05$. Spearman correlation test was also used for continuous/categorical variables against another categorical variable (more than 2 categories each), considering a confidence interval $(\mathrm{Cl})$ of $95 \%$ and significance of $5 \%$.

\section{Results}

Table 1 shows the distribution of protection equipment use according to equipment type and number of orthopedic surgeons in the study. Among 258 participants, 256 (99.2\%) used some kind of radiation protection, and $2(0.8 \%)$ used none. Additionally, 170 (65.9\%) only used the apron as protection, and 68 (26.3\%) used the apron and thyroid shield. Only $5.8 \%$ used the apron, thyroid shield, and radiation protection glasses (Table 1).

\begin{tabular}{lll}
\hline Protection Equipment & Frequency & $\%$ \\
\hline Hospital Apron & 169 & 65.5 \\
Hospital Apron + Thyroid shield & 67 & 25.9 \\
Hospital Apron + Thyroid shield + Spectacles & 13 & 5.0 \\
Hospital Apron + Spectacles & 2 & 0.8 \\
Own Apron & 1 & 0.4 \\
Own Apron + Thyroid shield & 1 & 0.4 \\
Own Apron + Thyroid shield + Spectacles & 2 & 0.8 \\
Own Apron + Spectacles & 1 & 0.4 \\
None & 2 & 0.8 \\
Total & $\mathbf{2 5 8}$ & $\mathbf{1 0 0}$ \\
\hline
\end{tabular}

Table 1. Types and frequency of protection equipment use 
Table 2 shows the frequency of radiation protection equipment use by specialty. Orthopedic trauma surgeons used the most protection equipment, with $47 \%$ using two or more items. In contrast, shoulder and pediatric surgeons had the lowest percentages of equipment use, $15 \%$ and $0 \%$ ( $\geq$ two or more items of equipment), respectively. They were also the only groups containing professionals who used no protection at all. According to Chi-square test, there is a statistically significant difference between the groups "no protection equipment used" and " $\geq$ two pieces of equipment used" (Table 2).

\begin{tabular}{lccc}
\hline \multirow{2}{*}{ Specialty } & \multicolumn{3}{c}{ Protection Equipment Use (Apron, Thyroid Shield, Spectacles) } \\
\cline { 2 - 4 } & None & One equipment & Z Two pieces of equipment use \\
\hline Knee & 0.00 & 32.00 & 6.00 \\
Hand & 0.00 & 14.00 & 3.00 \\
Shoulder & 1.00 & 16.00 & 3.00 \\
Foot and Ankle & 0.00 & 11.00 & 4.00 \\
Pediatric & 1.00 & 5.00 & 0.00 \\
Hip & 0.00 & 21.00 & 7.00 \\
Trauma & 0.00 & 71.00 & 63.00 \\
Total & $\mathbf{2 . 0 0}$ & $\mathbf{1 7 0 . 0 0}$ & $\mathbf{8 6 . 0 0}$ \\
p-value & $\mathbf{0 . 0 0 0 *}$ & $\mathbf{0 . 2 8 7}$ & $\mathbf{0 . 0 0 9 *}$ \\
\hline
\end{tabular}

*statistically significant: p-value $<0.05$

Table 2. Radiation protection equipment use by specialty

Table 3 shows the number of surgeries requiring fluoroscopy per week per surgeon and the gender distribution of surgeon offspring. Regarding radiation exposure affecting surgeon offspring, no statistically significant result was identified (Tables 3 and 4). No significant difference in offspring gender was apparent when analyzing each radiation exposure group (Table 3).

\begin{tabular}{lcccc} 
Surgeries that requires fluoroscopy per week per surgeon & Number of Participants & \multicolumn{2}{c}{ Offspring sex } & p-value \\
\cline { 2 - 5 } & & Male & Female & \\
\hline Less than 1 surgery & 7 & 4 & 1 & 0.19 \\
1 surgery & 25 & 6 & 6 & 0.96 \\
\hline 2 surgeries & 44 & 23 & 21 & 0.83 \\
\hline 3 surgeries & 54 & 26 & 18 & 0.27 \\
\hline 4 surgeries & 66 & 29 & 32 & 0.62 \\
\hline 5 surgeries & 35 & 11 & 16 & 0.62 \\
\hline More than 5 & 27 & 10 & 12 & 0.30 \\
\hline Total & 258 & 109 & 106 & \\
\hline
\end{tabular}

*statistically significant: $\mathrm{p}$-value $<0.05$

Table 3. Distribution of fluoroscopy use frequency and offspring sex 
Similarly, no significant difference was found when considering orthopedic surgeons who used equipment up to 2 times per week and those who used it 3 or more times per week (Table 4).

\begin{tabular}{|c|c|c|c|c|c|c|}
\hline Groups & $\begin{array}{l}\text { No of } \\
\text { offspring }\end{array}$ & $\begin{array}{l}\text { № of male } \\
\text { births }\end{array}$ & $\begin{array}{c}\text { Male proportion } \\
\text { (\%) }\end{array}$ & $\begin{array}{l}\text { Sex } \\
\text { Ratio }\end{array}$ & OR & $95 \% \mathrm{CI}$ \\
\hline \multirow{3}{*}{$\begin{array}{l}\text { Reference population } \\
\text { All irradiated groups }\end{array}$} & 91893674 & 46158225 & 50,23 & 1,01 & 1 & Reference \\
\hline & & & & & & $0,780-$ \\
\hline & 215 & 109 & 50,70 & 1,03 & 1,019 & 1,331 \\
\hline Until 2 surgeries per & & & & & & $0,076-$ \\
\hline week & 61 & 33 & 54,10 & 1,18 & 1,168 & 1,932 \\
\hline 3 or more surgeries per & & & & & & $0,074-$ \\
\hline week & 154 & 76 & 49,35 & 0,97 & 0,965 & 1,324 \\
\hline
\end{tabular}

Table 4. Fluoroscopy use and male proportions in offspring of male orthopedic surgeons

The dosimeter was not used by the majority of the sample, 136 participants $(52.7 \%)$ and only $22.1 \%$ always used it. No significant difference occurred with dosimeter use among all the specialties analyzed (Table 5).

\begin{tabular}{lcccc}
\hline \multirow{2}{*}{ Specialty } & \multicolumn{2}{c}{ Dosimeter use } & Total & p-value \\
\cline { 2 - 3 } & Yes & No & & \\
\hline Knee & 12 & 26 & 38 & 0.283 \\
Hand & 11 & 6 & 17 & \\
Shoulder & 11 & 9 & 20 & \\
Foot and Ankle & 8 & 7 & 15 & \\
Pediatric & 2 & 4 & 6 & \\
Hip & 12 & 16 & 28 & \\
Trauma & 66 & 68 & 134 & \\
Total & 122 & 136 & 258 & \\
\hline
\end{tabular}

Table 5. Comparison between specialty and dosimeter use

Occurrence of back pain presented no statistically significant difference when analyzing back pain and the use of lead apron (Table 6). Most of the individuals had back pain during long surgeries (82.2\%).

\begin{tabular}{|c|c|c|c|c|c|c|}
\hline \multirow[t]{2}{*}{ Back pain frequency } & \multicolumn{4}{|c|}{ Lead apron use } & \multirow[t]{2}{*}{ Total } & \multirow[t]{2}{*}{ p-value } \\
\hline & Yes & $\%$ & No & $\%$ & & \\
\hline Never & 99 & 38.7 & 2 & 100.0 & 101 & 0.209 \\
\hline Prolonged surgeries & 129 & 50.4 & 0 & 0.0 & 129 & \\
\hline All surgeries & 28 & 10.9 & 0 & 0.0 & 28 & \\
\hline Total & 256 & 100.0 & 2 & 100.0 & 258 & \\
\hline
\end{tabular}

Table 6. Comparison between back pain and lead apron use 
Regarding the variables of distance, tube plus radiation, exposed body parts, maximum annual dose, gestation maximum dose, and gestation period, no statistically significant difference occurred when comparing the knowledge of each specialist group across the variables mentioned in Table 7 (Table 7).

\begin{tabular}{lcc}
\hline Variable & Correlation Coefficient & p-value \\
\hline Distance & -0.036 & 0.562 \\
Tube plus Radiation & -0.018 & 0.777 \\
Exposed body parts & -0.035 & 0.581 \\
Annual maximum dose & -1.060 & 0.089 \\
Gestation maximum dose & -0.017 & 0.790 \\
Gestation period & -0.021 & 0.737 \\
\hline
\end{tabular}

Table 7. Analysis' results between specialties for each variable

No differences appeared regarding fluoroscope tube positioning, obesity, and radiation dose scenario. In this study, no individual orthopaedic surgery specialty appeared to have more knowledge about radiation (Table 8). 


\begin{tabular}{|c|c|c|c|c|c|c|}
\hline \multirow[t]{2}{*}{ Specialty } & \multicolumn{4}{|c|}{ Fluoroscope tube positioning } & \multirow[t]{2}{*}{ Total } & \multirow[t]{2}{*}{ p-value } \\
\hline & Below & $\%$ & Over & $\%$ & & \\
\hline Knee & 23 & 16.0 & 15 & 13.2 & 38 & 0.614 \\
\hline Hand & 7 & 4.9 & 10 & 8.8 & 17 & \\
\hline Shoulder & 11 & 7.6 & 9 & 7.9 & 20 & \\
\hline Foot and Ankle & 7 & 4.9 & 8 & 7.0 & 15 & \\
\hline Pediatric & 5 & 3.5 & 1 & 0.9 & 6 & \\
\hline Hip & 17 & 11.8 & 11 & 9.6 & 28 & \\
\hline Trauma & 74 & 51.4 & 60 & 52.6 & 134 & \\
\hline Total & 144 & 100.0 & 114 & 100.0 & 258 & \\
\hline \multirow[t]{2}{*}{ Specialty } & \multicolumn{4}{|c|}{ Obesity } & Total & p-value \\
\hline & Yes & $\%$ & No & $\%$ & & \\
\hline Knee & 26 & 18.2 & 12 & 10.4 & 38 & 0.408 \\
\hline Hand & 6 & 4.2 & 11 & 9.6 & 17 & \\
\hline Shoulder & 12 & 8.4 & 8 & 7.0 & 20 & \\
\hline Foot and Ankle & 7 & 4.9 & 8 & 7.0 & 15 & \\
\hline Pediatric & 3 & 2.1 & 3 & 2.6 & 6 & \\
\hline Hip & 15 & 10.5 & 13 & 11.3 & 28 & \\
\hline Trauma & 74 & 51.7 & 60 & 52.2 & 134 & \\
\hline Total & 143 & 100.0 & 115 & 100.0 & 258 & \\
\hline \multirow[t]{2}{*}{ Specialty } & \multicolumn{4}{|c|}{ Radiation dose in scenario (Question 15 of questionnaire) } & Total & p-value \\
\hline & Assistant & $\%$ & Surgeon & $\%$ & & \\
\hline Knee & 17 & 11.3 & 21 & 19.4 & 38 & 0.468 \\
\hline Hand & 9 & 6.0 & 8 & 7.4 & 17 & \\
\hline Shoulder & 13 & 8.7 & 7 & 6.5 & 20 & \\
\hline Foot and Ankle & 8 & 5.3 & 7 & 6.5 & 15 & \\
\hline Pediatric & 5 & 3.3 & 1 & 0.9 & 6 & \\
\hline Hip & 16 & 10.7 & 12 & 11.1 & 28 & \\
\hline Trauma & 82 & 54.7 & 52 & 48.1 & 134 & \\
\hline Total & 150 & 100.0 & 108 & 100.0 & 258 & \\
\hline
\end{tabular}

Table 8. Comparison between variables and specialties

\section{Discussion}

Since 1980, the United States has experienced a sixfold increase in medical radiation exposure. Estimates suggest that up to $3 \%$ of all future malignant neoplasia could be caused by previous ionizing radiation exposure [1]. Several studies, therefore, have been and are being conducted to gather information to develop education for using the best available evidence and technology, while preventing harm to patients and medical teams.

Currently, the literature contains conflicting evidence regarding some effects of ionizing radiation. One interesting idea is that daily radiation exposure in male doctors while working may increase the chances of producing female offspring. Zadeh and Briggs published one of the first related studies in 1997. They reported that male obstetricians, gynecologists, and orthopedic surgeons in the United Kingdom had a higher incidence of female offspring [7]. In addition, an increased risk for congenital abnormalities was present, and a statistical difference existed in all the findings compared to the population [7]. Since the 
obstetricians and gynecologists were not exposed to radiation, Zadeh and Briggs proposed that occupational exposure to x-ray was not associated with the findings, and the possible cause was exposure to the operating theatre environment [7]. However, Hama et al. from Japan divided participants of his study into two groups, "lightly irradiated" and "highly irradiated" (one or more incidents of annual radiation exposure $>10 \mathrm{mSv}$ ). They found a significant statistical increase in the risk of radiologists from the "highly irradiated" group producing a lower proportion of male offspring [8]. The most recent study on this topic published by Choi et al. used a sample of male invasive cardiologists. The authors found no significant difference in the proportion of male and female offspring, even when analyzing a subgroup with higher radiation exposure [9]. In the present study, we found similar results to Choi et al. and Zadeh and Briggs. No difference was identified in the proportion of male offspring born to male orthopedic surgeons in Brazil. The proportions were similar to the Brazilian population. We also compared a group of lower radiation exposure to one of higher exposure, determined by the number of surgeries requiring fluoroscopy per week per surgeon. Again, no difference was found in offspring gender proportion.

Another controversial topic is the relationship between lead apron use and back pain in orthopedic surgeons or professionals that deal with $x$-rays. To our knowledge, the first study investigating this relationship was published by Moore et al. and did not prove lead apron use as a risk factor for back pain [10]. Later, research on the prevalence of spinal disc disease among interventional cardiologists argued the existence of the "interventionalist's disc disease". It reported significant differences between the incidence of skeletal complaints among interventional cardiologists compared to orthopedists and rheumatologists [11]. Their study showed a greater incidence of cervical, rather than lumbar, problems. It was also noted that interventional cardiologists use aprons for longer periods, which increases the impact on the axial skeleton [12]. However, our study produced results similar to Moore. No significant relationship occurred between back pain frequency and apron use among orthopedic surgeons in Brazil, but the descriptive analysis showed that most of our participants complained of back pain during prolonged surgeries. Therefore, we think that more hours of apron use might be necessary to cause harmful effects and related back pain, similar to the study of interventional cardiologists. Even without apron use, prolonged procedures might be a cause of back pain, although we have yet to see a study comparing both situations.

Our study also assessed how orthopedic surgeons in Brazil protect themselves from occupational ionizing radiation and whether they know the theory behind prevention from harmful x-rays.

Unfortunately, the results showed a lack of radiation protection equipment use and lack of knowledge about basic radiation prevention. In our sample, $65.9 \%$ only used the apron as protection equipment despite the well-known fact that radiation is the main risk factor for thyroid cancer. Only $32.1 \%$ used at least the apron and thyroid shield, and $5.8 \%$ used the apron, thyroid shield, and radiation protection glasses. The dosimeter was not used by the majority, $52.7 \%$, and only $22.1 \%$ always used it. A study about fluoroscopic radiation exposure highlighted that surgeon eyes and hands receive more radiation than other body parts, and therefore surgeons should routinely use eye and hand protection in addition to the apron and thyroid shield [13]. It is noteworthy that a study published by Muir et al. showed that some aprons were labeled as having higher protection than they in fact presented when tested[14]. 
Regarding the questions on radiation prevention knowledge, most of the orthopedic surgeons answered poorly. Only $2.7 \%$ reached the acceptable annual maximum permissible radiation dose. Just $10.5 \% \mathrm{knew}$ the period of greater risk to the fetus when exposed to $x$-rays, and $5.8 \%$ reached the maximum permissible radiation dose during pregnancy. About one quarter, $25.2 \%$, knew that 3 meters or more from the radiation-emitting tube is considered the safe distance, and $44.2 \%$ knew the safest positioning of the radiation-emitting tube. Only $25.2 \%$ knew that smaller tubes generally emit greater radiation at the entrance dose to magnify the image. Just over half, $55.4 \%$, knew that the surgery team receives more scattered radiation in surgical procedures performed on obese patients. Finally, the question if the hand, eyes, and thyroid are the most exposed and at greater risk of radiation-related lesions was correctly answered by only $58.5 \%$ of participants.

No significant differences in knowledge were found when comparing all orthopedic surgery specialties. All specialties performed similarly. It seems that the poor performance on the survey is not limited to Brazil. An original study in 2013 showed that orthopedic surgeons from Canada lacked knowledge about the risk of eye cataracts when exposed to radiation, and $75 \%$ were unaware of radiation dose limits [15]. A survey analysis from Turkey demonstrated inadequate knowledge about the uses and risks of fluoroscopy and radiation prevention [16]. Another article from Latin America showed that $75.7 \%$ of their sample rarely or never used a dosimeter badge, and only $20.2 \%$ used lead glasses in their practice. The article also highlighted significant differences and many knowledge deficiencies among countries [17].

An interventional study was performed to analyze the effect of surgeon education about radiation protection [18]. The educational intervention was applied to surgeons performing complex endovascular procedures. A strong relationship $(p<0.001)$ between the intervention and decrease in radiation dose was found, excluding cases of fenestrated endovascular aneurysm repair which continued to present high radiation exposure [18]. Additionally, some articles summarize the main important aspects of how to decrease unnecessary radiation exposure, by explaining radiation effects, dose, and protection equipment. These articles highlight that minimally invasive surgery increases radiation exposure, especially in cases of spinal surgery $[19,20]$. The concepts of ALARA (as low as reasonably achievable) and DEBT (distance, exposure, barriers, and time) are highlighted as pillars of practical guidelines [2-6, 21].

As a main limitation, our study design and sample characteristics preclude concluding that orthopaedic surgeons worldwide present the same knowledge regarding radiation exposure and safety procedures to avoid harmful effects. Another limitation is the lack of uniformity among subspecialties. We had 134 trauma surgeons versus 6 pediatric surgeons, 15 foot and ankle surgeons, and 17 hand surgeons, potentially limiting comparison among specialists in terms of knowledge and other variables analyzed in the study. Nevertheless, by focusing on basic education for medical residents before specialization, we feel our data demonstrates quite clearly that orthopedic practitioners present a low level of knowledge regarding the harmful effects of radiation exposure.

\section{Conclusions}


Our study reveals that orthopaedic surgeons in Brazil presented inadequate performance regarding theoretical and practical knowledge about radiation exposure. No significant differences were found when comparing knowledge in any topic among all orthopedic surgery specialties. Furthermore, only the minority of orthopaedic surgeons used the basic radiation protection equipment (apron, thyroid shield, and radiation protection glasses). The data in this study highlight an urgent need to create education for orthopedic surgeons and orthopedic surgery residents in Brazil, and possibly worldwide, to decrease patient and surgeon exposure to ionizing radiation. Personal protection and implementation of the ALARA protocol in daily practice are important behaviors to help prevent the harmful effects of ionizing radiation.

\section{List Of Abbreviations}

Cl: Confidence Interval

mSv: milisievert

ALARA: As Low As Reasonably Achievable

DEBT: Distance, Exposure, Barriers, and Time

\section{Declarations}

\section{Acknowledgements}

Not applicable.

\section{Funding}

No funding was involved to support this study.

\section{Competing interests}

The authors declare that they have no competing interests related with this article.

\section{Ethics and Consent for publication}

Ethical approval was obtained by the Department Assembly at Federal University of Minas Gerais. The manuscript contains no individual personal data. No consent for publication was necessary.

\section{Author's information / Affiliations}

REP, IGNR, and ARVF: Departamento do Aparelho Locomotor, Universidade Federal de Minas Gerais, Belo Horizonte, MG, Brazil 
VG: Serviço de Ortopedia e Traumatologia Prof. Nova Monteiro, Hospital Municipal Miguel Couto, Rio de Janeiro, RJ, Brazil

PJP: Departamento de Ortopedia e Traumatologia, Universidade Federal Fluminense, Niterói, RJ, Brazil

WDB: Departamento de Ortopedia e Traumatologia, Universidade Estadual de Campinas (Unicamp), Campinas, SP, Brazil

\section{Author's Contributions}

REP and IGNR had substantial contributions to the conception of the work, acquisition of data, analysis and interpretation of data and drafting the article. ARVF gathered and managed data. VG, PJP, and WDB had substantial contributions to the conception of the work and revised the draft critically for important intellectual content. All authors read and approved the final manuscript.

Availability of data and materials

The datasets generated and/or analyzed during the current study are available in the author's database.

\section{Footnote}

Radiation Exposure Dangers Questionnaire is available as a supplementary file.

\section{References}

1. Linet MS, Slovis TL, Miller DL, Kleinerman R, Lee C, Rajaraman P, et al. Cancer risks associated with external radiation from diagnostic imaging procedures. CA Cancer J Clin. 2012;62(2):75-100.

2. Kaplan DJ, Patel JN, Liporace FA, Yoon RS. Intraoperative radiation safety in orthopaedics: a review of the ALARA (As low as reasonably achievable) principle. Patient Safety in Surgery. 2016;10(27):1-7.

3. Massalha S, Almufleh A, Small G, Marvin B, Keidar Z, Israel O, Kennedy JA. Strategies for Minimizing Occupational Radiation Exposure in Cardiac Imaging. Curr Cardiol Rep.2019 Jun 21;21(8):71. doi: 10.1007/s11886-019-1157-1.

4. Pasha K, Khan HR, Sumon AA. Staying Safe from Radiation Exposure in Cath Lab: A Review. Mymensingh Med J.2018 Apr;27(2):437-9.

5. Tack D, Nicaise N. Guidelines in medical imaging : objectives, limits and radiation protection. Rev Med Brux.2018;39(4):399-405.

6. Hak DJ. Radiation exposure during intramedullary nailing. Injury.2017 Jun;48 Suppl 1:S26-S9.

7. Zadeh HG, Briggs TWR. lonising radiation: are orthopaedic surgeons' offspring at risk? Ann R Coll Surg Engl. 1997;79(3):214-20.

8. Hama Y, Uematsu M, Sakurai Y, Kusano S. Sex Ratio in the Offspring of Male Radiologists. Academic Radiology. 2001;8(5):421-4. 
9. Choi JW, Mehrotra P, MacDonald LA, Klein LW, Linsky NM, Smith AM, et al. Sex proportion of offspring and exposure to radiation in male invasive cardiologists. Proc (Bayl Univ Med Cent). 2007;20(3):231-4.

10. Moore B, vanSonnenberg E, Casola G, Novelline RA. The Relationship Between Back Pain and Lead Apron Use in Radiologists. American Journal of Roentgenology. 1992;158(1):191-3.

11. Ross AM, Segal J, Borenstein D, Jenkins E, Cho S. Prevalence of Spinal Disc Disease Among Interventional Cardiologists. Am J Cardiol. 1997;79(1):68-70.

12. Livingstone RS, Varghese A, Keshava SN. A Study on the Use of Radiation-Protective Apron among Interventionists in Radiology. J Clin Imaging Sci. 2018;8:34.

13. Hoffler CE, llyas AM. Fluoroscopic radiation exposure: are we protecting ourselves adequately? J Bone Joint Surg Am. 2015;97(9):721-5.

14. Muir S, McLeod R, Dove R. Light-weight lead aprons - light on weight, protection or labelling accuracy? Australasian Physical \& Engineering Sciences in Medicine. 2005;28(2):128-30.

15. Chow R, Beaupre LA, Rudnisky CJ, Otto D, Clark M. Surgeon's Perception of Fluoroscopic Radiation Hazards to Vision. American Journal of Orthopedics. 2013;42(11):505-10.

16. Tuncer N, Kuyucu E, Sayar S, Polat G, Erdil I, Tuncay I. Orthopedic surgeons' knowledge regarding risk of radiation exposition: a survey analysis. SICOT J. 2017;3:29.

17. Falavigna A, Ramos MB, lutaka AS, Menezes CM, Emmerich J, Taboada N, et al. Knowledge and Attitude Regarding Radiation Exposure Among Spine Surgeons in Latin America. World Neurosurg. 2018;112:e823-e9.

18. Kirkwood ML, Arbique GM, Guild JB, Timaran C, Chung J, Anderson JA, et al. Surgeon education decreases radiation dose in complex endovascular procedures and improves patient safety. J Vasc Surg. 2013;58(3):715-21.

19. Giordano BD, Grauer JN, Miller CP, Morgan TL, Rechtine GR, 2nd. Radiation exposure issues in orthopaedics. J Bone Joint Surg Am. 2011;93(12):e69(1-10).

20. Yu E, Khan SN. Does less invasive spine surgery result in increased radiation exposure? A systematic review. Clin Orthop Relat Res. 2014;472(6):1738-48.

21. Hill KD, Einstein AJ. New approaches to reduce radiation exposure. Trends Cardiovasc Med. 2016;26(1):55-65.

\section{Supplementary Files}

This is a list of supplementary files associated with this preprint. Click to download.

- Survey.Supportinglnformation.pdf 